\title{
Gravidade e lesões traumáticas em vítimas de acidente de trânsito internadas em um hospital público
}

\author{
Severity and traumatic injuries in traffic accident victims in a public hospital \\ La gravedad y las lesiones traumáticas en las víctimas de accidente de tráfico de pacientes \\ internados en un hospital público
}

\section{RESUMO}

Objetivo: Identificar as principais lesões das categorias de vítimas em acidentes de trânsito e sua gravidade. Método: Estudo quantitativo, transversal, com 276 vítimas internadas e, a partir de dados de prontuários e entrevistas, foi realizada associação logística para análises. Resultados: Houve maior frequência do sexo masculino (78,9\%), na faixa etária de 21 a 39 anos (50,3\%) e motociclistas (74,6\%). A lesão mais comum: fratura fechada $(44,5 \%)$ em membros inferiores (41,9\%). A ocorrência de lesão cerebral, lesão torácica e idade aumentam a chance de trauma grave, enquanto o estado civil casado diminui a chance, independente do sexo. Conclusão: Assim, vale destacar que os dados apresentados são fundamentais, para o processo de enfermagem no trauma, visto que as lesões de membros inferiores com fraturas são destaques na categoria de motociclistas e que juntamente com as lesões cerebrais e torácicas incrementam a mortalidade nessas ocorrências.

Descritores: Acidentes de Trânsito; Ferimentos e Lesões; Causas Externas; Epidemiologia Analítica.

\begin{abstract}
Objective: To identify the main injuries and their severity in the categories of traffic accidents victims. Method: This is a quantitative, cross-sectional study, with 276 hospitalized victims, based on data from medical records and interviews, with a logistical association for analysis. Results: There was a higher frequency of males (78.9\%), aged 21 to 39 years (50.3\%) and motorcyclists (74.6\%). The most common injury: closed fracture (44.5\%) in the lower limbs (41.9\%). The occurrence of brain injury, chest injury and age increase the chance of serious trauma, while married marital status decreases the chance, regardless of sex. Conclusion: These data are fundamental for the nursing process in trauma, since lower limb injuries with fractures are the most common in the category of motorcyclists and that, together with brain and thoracic injuries, increases mortality in these occurrences.

Descriptors: Accidents; Traffic; Wounds and Injuries; External Causes; Analytical Epidemiology.
\end{abstract}

\section{RESUMEN}

Objetivo: Identificar las principales lesiones de las categorías de víctimas en accidentes de tráfico y su gravedad. Método: Estudio cuantitativo, transversal, con 276 víctimas hospitalizadas, basado en datos de historias clínicas y entrevistas, con una asociación logística para análisis. Resultados: Hubo una mayor frecuencia de hombres (78,9\%), de 21 a 39 años $(50,3 \%)$ y motociclistas $(74,6 \%)$. La lesión más común: fractura cerrada $(44,5 \%)$ en miembros inferiores (41,9\%). La aparición de lesiones cerebrales, lesiones en el pecho y la edad aumentan la posibilidad de un traumatismo grave, mientras que el estado civil casado disminuye la posibilidad, independientemente del sexo. Conclusión: Por lo tanto, cabe destacar que los datos presentados son fundamentales para el proceso de enfermería en traumatismo, ya que las lesiones en las extremidades inferiores con fracturas se destacan en la categoría de motociclistas y que junto con las lesiones cerebrales y torácicas aumentan la mortalidad en estos sucesos.

Descriptores: Accidentes de Tráfico; Heridas y Traumatismos; Causas Externas; Epidemiología Analítica.

Greiciane Silva Rocha ${ }^{1}$
(D) $\underline{0000-0002-1636-7179}$
Catharine Ávila da Silva ${ }^{2}$
(D) $\underline{0000-0003-1974-8214}$
Letícia Vieira Crispim ${ }^{1}$
(D) $\underline{0000-0001-9501-7830}$

1 Universidade Federal do Acre.

2 Polícia Militar do Estado do Acre.
Autor correspondente: Greiciane da Silva Rocha E-mail: greiciane.rocha@ufac.br

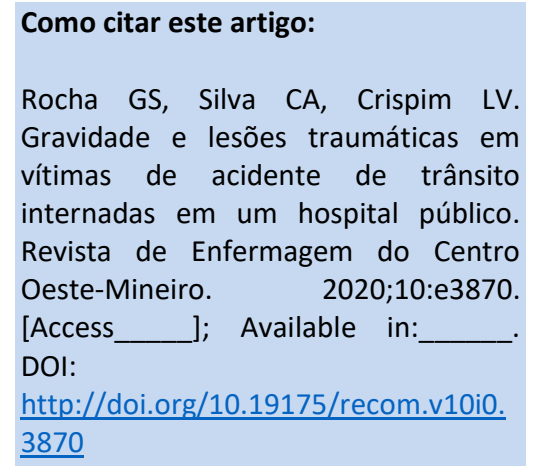




\section{INTRODUÇÃO}

Os acidentes de trânsito (AT) têm se colocado como uma das principais causas de morte, ocupando a 9a posição no mundo. Dentre as vítimas fatais, $50 \%$ são pedestres, motociclistas e ciclistas e, do total de vítimas, $75 \%$ são do sexo masculino, sendo a principal causa de morte na faixa etária de 15-29 anos $^{(1-2)}$. O Brasil, no ano de 2018, apresentava taxa de mortalidade de $16,1 / 100.000$ habitantes. No ranking nacional, a região Norte ocupava a quarta colocação $(17,2 / 100.000 \text { habitantes) })^{(3)}$. No Estado do Acre, a mortalidade se apresentou, em 2018, com uma taxa de 1,19 e Rio Branco, capital do Estado, com uma taxa de 1,15 (ambos por 10.000 habitantes). No tocante à morbidade, uma taxa de 11,8 e 17,2 por 10.000 habitantes, no Acre e Rio Branco, respectivamente ${ }^{(3-4)}$. Com uma taxa de mortalidade reduzida, Estado e município seguem em destaque nas internações, a partir de uma assistência pré-hospitalar e hospitalar qualificada, as quais levam ao aumento da sobrevida, porém, em decorrência da gravidade do trauma, as sequelas têm-se apresentado nas vítimas de acidentes de tráfego.

Assim, os ATs são responsáveis por grande número de lesões não fatais, segundo a Organização Mundial de Saúde (OMS). Para cada morte em acidentes, há pelo menos vinte outras vítimas que sofrem com esse tipo de lesão. Em 2018, o Brasil contou com 209.571 casos de internação e um grande número de seguros por invalidez pagos pelo seguro de Danos Pessoais Causados por Veículos Automotores de Via Terrestre (DPVAT). A região Norte foi responsável por $11 \%$ das internações, nesse período, com 23.237 pacientes, dentro as quais o estado do Acre esteve presente com 1.111 casos $^{(1,4)}$.

As lesões mais frequentes em acidentes de trânsito são: fraturas, contusões, luxações, escoriações, injúrias cerebrais e medulares. Elas atingem inúmeras regiões do corpo, a depender do mecanismo do trauma, como extremidades, quadril, cabeça, face, tórax e abdômen. Dentre os agravos decorrentes desse evento traumático, as que mais acometem motociclistas são as musculoesqueléticas, localizadas principalmente nos membros inferiores/quadril, membros superiores, superfície externa e cabeça. Nos pedestres, ocorrem mais contusões, fraturas e lesões cerebrais, sendo a cabeça, pescoço, face, extremidades e tórax as regiões mais atingidas, tornando essas as vítimas fatais mais frequentes.
Os ciclistas, assim como os pedestres, apresentam, sobretudo, contusões, fraturas e lesões cerebrais, e as regiões mais atingidas são extremidades, cabeça e tronco. Ocupantes de veículo fechado apresentam, em especial, contusões, fraturas e lacerações, e as partes do corpo mais atingidas são face, tórax, abdômen e extremidades ${ }^{(5-7)}$.

Nesse contexto, 0 atendimento ao traumatizado pela equipe de enfermagem exige uma nova forma de atuação que rompa com o modelo biomédico, por meio da lei 7.498 de 1986, em que foi estabelecida a implementação da sistematização da assistência de enfermagem, apontando as atividades privativas do enfermeiro, como a realização dos procedimentos de alta complexidade e a confecção dos diagnósticos de enfermagem que, baseada em evidências, contribuem para a escolha da melhor intervenção e os melhores resultados ${ }^{(8-10)}$.

O conhecimento do tipo de lesão e seu nível de gravidade é decisivo para orientação na conduta e nível de complexidade hospitalar exigido no atendimento à vítima do trauma. Sendo assim, o presente trabalho tem como objetivo identificar as principais lesões que acometem as categorias de pedestre, motociclista, ciclista e usuário de automóvel em acidentes de trânsito bem como sua gravidade.

\section{MÉTODOS}

Trata-se de um estudo quantitativo, com delineamento transversal, desenvolvido no Hospital de Urgência e Emergência, sendo essa única porta de entrada de emergência pública do município e referência para municipalidades vizinhas, como, por exemplo, as cidades do estado do Amazonas, Rondônia e países vizinhos, a citar Peru e Bolívia. A amostra foi não probabilística por conveniência de 276 vítimas de acidentes de trânsito, internadas no período de novembro 2016 a abril de 2017, no município de Rio Branco, capital do Estado do Acre.

Foram inseridos na pesquisa indivíduos que haviam sofrido trauma por acidente de trânsito, os quais deveriam possuir guia de Autorização de Internação Hospitalar (AlH) aberta. Também foram incluídos casos com 24 horas de internação, que já possuíam prescrição médica diária e aguardavam avaliação de especialistas. Os motivos de exclusão de casos foram evasão, óbito e transferência hospitalar.

Para a coleta de dados, foram utilizados um questionário e um formulário resumidos, pré- 
testados, adaptados e categorizados para busca de informações inerentes a vítimas e aos registros hospitalares ${ }^{(11)}$. Em uma primeira abordagem, realizou-se a aplicação do questionário com a vítima acidentada e teve como objetivo identificar e qualificar as vítimas envolvidas nos acidentes de trânsito. Essa compilação de questões foi dividida em três categorias: 1.Identificação, 2.Dados sociodemográficos e 3.Dados relacionados ao acidente de trânsito.

Quanto aos dados coletados, a partir dos prontuários e boletins de atendimentos, foi utilizado um formulário resumido, dividido em: 1Dados Gerais, 2-Dados do trauma e lesão, 3Cirurgia e 4-Lesões e Códigos, que norteavam a mensuração das lesões apresentadas pelas vítimas. Para a categorização das lesões, utilizou-se o capítulo XIX das lesões da Classificação Estatística Internacional de Doenças e Problemas Relacionados com a Saúde (CID-10), em específico, as de S00 a T98, excluindo categorias que não contemplavam a classificação para vítimas de acidente de trânsito.

Após a categorização, realizou-se a análise da severidade das lesões pelo Abbrevieated Injury Scale (AIS). Esse instrumento classifica as lesões decorrentes do trauma por região anatômica, atribuindo um escore de gravidade com variação de 1 a 6 , sendo AIS 1 leve, AIS 2 moderada, AIS 3 séria, AIS 4 grave, AIS 5 crítica e AIS 6 máxima. Após a classificação, todos os dados analisados foram utilizados para calcular a gravidade do trauma pelo New Injury Severity Score (NISS). O instrumento considera o cálculo das três lesões mais graves, independente da região corpórea, classificando o trauma em grave, moderado e leve.

Todos os dados coletados foram codificados e organizados utilizando o software Microsoft Excel (versão 2013). Na análise descritiva dos dados, foram estimadas distribuições de frequências, médias e desvios-padrão nas variáveis contínuas.
Para as variáveis categóricas estimadas as proporções. As diferenças entre os grupos foram consideradas com o teste de Qui-quadrado de Pearson e teste-t student. Em todas as análises, foi utilizado índice de significância de 5\%. A análise da associação foi feita, por meio de regressão logística múltipla, pelo software STATA 13.0 e adotado um nível de significância $p<0,05$ e IC 95\%.

O estudo recebeu parecer favorável do comitê de ética e pesquisa (CEP) da Universidade Federal do Acre (parecer $n^{\circ}$ 1.820.536), obedecendo aos critérios da resolução do Conselho Nacional de Saúde (CNS) 466/2012, preservando o anonimato dos participantes.

\section{RESULTADOS E DISCUSSÃO}

A pesquisa obteve como resultado 276 vítimas, com predominância do sexo masculino (78,9\%). Do total de vítimas, 17 eram pedestres, 25 ciclistas, 23 ocupantes de veículo fechado e, em maior número, estavam os motociclistas com 211 casos. Com relação à idade, a maioria das vítimas eram jovens, sendo 25,3\% na faixa entre $21-29$ anos e as características das vítimas podem ser observadas na Tabela 1.

Quanto aos acidentes, a maioria ocorreu em dias úteis da semana (61,9\%), no período vespertino (42\%). Os tipos de acidentes mais presentes foram as colisões/abalroamento $(61,2 \%)$. Mais dados podem ser visualizados na Tabela 2.

Em se tratando de lesões, foram encontradas 459, a predominância foi de fraturas fechadas (53,3\%). As escoriações apareceram em $11,5 \%$ dos casos. O trauma crânio encefálico (TCE) representou 7,8\%, a categoria que mais apresentou esse tipo de lesão foram os motociclistas $(63,8 \%)$ e ciclistas $(19,4 \% \%)$, como podem ser observados na Tabela 3.

Tabela 1 - Características de vítimas de acidente de trânsito internadas, em um hospital público do município de Rio Branco, AC, no período de novembro de 2016 a abril de 2017

\begin{tabular}{|c|c|c|c|c|c|c|c|c|c|c|}
\hline \multirow[t]{2}{*}{ Variável } & \multicolumn{2}{|c|}{ Motociclista } & \multicolumn{2}{|c|}{$\begin{array}{l}\text { Ocupante de Veículo } \\
\text { fechado }\end{array}$} & \multicolumn{2}{|c|}{ Pedestre } & \multicolumn{2}{|c|}{ Ciclista } & \multicolumn{2}{|c|}{ Total } \\
\hline & $\mathrm{N}$ & $\%$ & $\mathrm{~N}$ & $\%$ & $\mathrm{~N}$ & $\%$ & $\mathrm{~N}$ & $\%$ & $\mathrm{~N}$ & $\%$ \\
\hline \multicolumn{11}{|l|}{ Sexo } \\
\hline Masculino & 173 & 79.3 & 16 & 7.3 & 12 & 5.5 & 17 & 7.7 & 218 & 78.9 \\
\hline Feminino & 38 & 65.5 & 7 & 12 & 5 & 8.6 & 8 & 13.7 & 58 & 21.1 \\
\hline
\end{tabular}


4|Rocha GS, Silva CA, Crispim LV

Tabela 1 - Características de vítimas de acidente de trânsito internadas, em um hospital público do município de Rio Branco, AC, no período de novembro de 2016 a abril de 2017

\begin{tabular}{|c|c|c|c|c|c|c|c|c|c|c|}
\hline \multirow[t]{2}{*}{ Variável } & \multicolumn{2}{|c|}{ Motociclista } & \multicolumn{2}{|c|}{$\begin{array}{l}\text { Ocupante de Veículo } \\
\text { fechado }\end{array}$} & \multicolumn{2}{|c|}{ Pedestre } & \multicolumn{2}{|c|}{ Ciclista } & \multicolumn{2}{|c|}{ Total } \\
\hline & $\mathrm{N}$ & $\%$ & $N$ & $\%$ & $\mathrm{~N}$ & $\%$ & $\mathrm{~N}$ & $\%$ & $\mathrm{~N}$ & $\%$ \\
\hline \multicolumn{11}{|l|}{ Faixa etária } \\
\hline $0-10$ & - & - & - & - & 4 & 66.6 & 2 & 33.3 & 6 & 2.1 \\
\hline $11-20$ & 34 & 79 & 4 & 9.3 & 2 & 4.6 & 3 & 6.9 & 43 & 15.5 \\
\hline $21-29$ & 59 & 84.2 & 6 & 8.5 & - & - & 5 & 7.1 & 70 & 25.3 \\
\hline $30-39$ & 56 & 81.1 & 3 & 4.3 & 5 & 7.2 & 5 & 7.2 & 69 & 25 \\
\hline $40-49$ & 41 & 80.3 & 3 & 5.8 & - & - & 7 & 13.7 & 51 & 18.4 \\
\hline $50-59$ & 12 & 60 & 5 & 25 & 1 & 5 & 2 & 10 & 20 & 7.2 \\
\hline $60-69$ & 9 & 64.2 & 2 & 14.2 & 2 & 14.2 & 1 & 7.1 & 14 & 5 \\
\hline $70-79$ & - & - & - & - & 2 & 100 & - & - & 2 & 0.7 \\
\hline Mais de 80 & - & - & - & - & 1 & 100 & - & - & 1 & 0.3 \\
\hline \multicolumn{11}{|l|}{ Estado civil } \\
\hline Solteiro & 123 & 85.4 & 7 & 4.8 & 5 & 3.4 & 9 & 6.2 & 144 & 52.1 \\
\hline Casado/amasiado & 68 & 71.5 & 11 & 11.5 & 4 & 4.2 & 12 & 12.6 & 95 & 34.4 \\
\hline Separado/Viúvo & 19 & 67.8 & 5 & 17.8 & 3 & 10.7 & 1 & 3.5 & 28 & 10.1 \\
\hline $\begin{array}{l}\text { Outros (menor de } \\
\text { idade) }\end{array}$ & 1 & 11.1 & - & - & 5 & 55.5 & 3 & 33.3 & 9 & 3.2 \\
\hline TOTAL & & & & & & & & & 276 & 100 \\
\hline
\end{tabular}

Fonte: Pesquisa de campo.

Tabela 2 - Características dos acidentes de trânsito em vítimas internadas, em um hospital público do município de Rio Branco, AC, no período de novembro de 2016 a abril de 2017

\begin{tabular}{|c|c|c|c|c|c|c|c|c|c|c|}
\hline \multirow[t]{2}{*}{ Variável } & \multicolumn{2}{|c|}{ Motociclista } & \multicolumn{2}{|c|}{$\begin{array}{l}\text { Ocupante de } \\
\text { Veículo fechado }\end{array}$} & \multicolumn{2}{|c|}{ Pedestre } & \multicolumn{2}{|c|}{ Ciclista } & \multicolumn{2}{|c|}{ Total } \\
\hline & $\mathrm{N}$ & $\%$ & $N$ & $\%$ & $\mathrm{~N}$ & $\%$ & $\mathrm{~N}$ & $\%$ & $\mathrm{~N}$ & $\%$ \\
\hline \multicolumn{11}{|l|}{ Dia da semana } \\
\hline Fim de semana & 75 & 74.2 & 11 & 10.8 & 8 & 7.9 & 7 & 6.9 & 101 & 36.5 \\
\hline Durante a semana & 134 & 78.3 & 11 & 6.4 & 9 & 5.2 & 17 & 9.9 & 171 & 61.9 \\
\hline Não sabe/ não lembra & 2 & 50 & 1 & 25 & - & - & 1 & 25 & 4 & 1.4 \\
\hline \multicolumn{11}{|l|}{ Período } \\
\hline Matutino & 60 & 81 & 5 & 6.7 & 4 & 5.4 & 5 & 6.7 & 74 & 26.8 \\
\hline Vespertino & 87 & 75 & 11 & 9.4 & 8 & 6.8 & 10 & 8.6 & 116 & 42 \\
\hline Noturno & 46 & 75.4 & 5 & 8.1 & 5 & 8.1 & 5 & 8.1 & 61 & 22.1 \\
\hline Madrugada & 15 & 88.2 & 2 & 11.7 & - & - & - & - & 17 & 6.1 \\
\hline Não sabe/ não lembra & 3 & 100 & - & - & - & - & - & - & 3 & 1 \\
\hline \multicolumn{11}{|l|}{ Tipo de acidente } \\
\hline $\begin{array}{l}\text { Colisão/abalroamento/ colisão com } \\
\text { animal }\end{array}$ & 140 & 82.3 & 11 & 6.4 & - & - & 18 & 10.5 & 169 & 61.2 \\
\hline Tombamento/capotamento & 24 & 72.7 & 6 & 18.1 & - & - & 2 & 6 & 32 & 11.5 \\
\hline Atropelamento & - & - & - & - & 16 & 100 & & - & 16 & 5.7 \\
\hline Choque com objeto fixo & 17 & 85 & 2 & 10 & - & - & 1 & 5 & 20 & 7.2 \\
\hline Queda & 20 & 83.3 & 1 & 4.1 & - & - & 3 & 12.5 & 24 & 8.6 \\
\hline Saída da pista & 5 & 71.4 & 2 & 28.6 & - & - & - & - & 7 & 2.5 \\
\hline Não sabe/ não lembra & 4 & 66.6 & 1 & 16.6 & 1 & 16.6 & - & - & 6 & 2.1 \\
\hline TOTAL & & & & & & & & & 276 & 100 \\
\hline
\end{tabular}

Fonte: Pesquisa de campo.

Quanto ao segmento anatômico, o mais atingido foi o de membros inferiores (41,9\%). A região de cabeça e face $(13,4 \%)$ foi mais acometida em motociclistas e ciclistas, $70,1 \%$ e $15 \%$, respectivamente, conforme observado na Tabela 3.

A gravidades das lesões foi verificada pelo AIS e divididas em três grupos: graves, moderadas e leves. Houve predominância de lesões moderadas $(n=271)$, seguidas de graves $(n=101)$ e leves $(n=87)$. As mais graves com AIS $>3$ foram fraturas expostas $(n=33)$, seguidas de fraturas fechadas $(n=17)$ e TCEs $(n=17)$. A categoria de pedestres apresentou 10\% de vítimas com lesões AIS > 3 e $90 \%$ AIS < 3 , os motociclistas apresentaram $20,1 \%$ com AIS $>3$ e $79,8 \%$ com AIS $<3$, os ciclistas contaram com $24,3 \%$ AIS $>3$ e $75,6 \%$ AIS $<3$, por fim, os ocupantes de veículo fechado tiveram $36,5 \%$ casos AIS > 3 e $63,4 \%$ AIS < 3. 
Tabela 3 - Caracterização das lesões de vítimas de acidente de trânsito internadas, em um hospital público do município de Rio Branco, AC, no período de novembro de 2016 a abril de 2017

\begin{tabular}{|c|c|c|c|c|c|c|c|c|c|c|}
\hline \multirow{2}{*}{ Variável } & \multicolumn{4}{|c|}{$\begin{array}{c}\text { Ocupante de Veículo } \\
\text { fechado }\end{array}$} & \multicolumn{2}{|c|}{ Pedestre } & \multicolumn{2}{|c|}{ Ciclista } & \multicolumn{2}{|c|}{ Total } \\
\hline & $\mathrm{N}$ & $\%$ & $N$ & $\%$ & $\mathrm{~N}$ & $\%$ & $\mathrm{~N}$ & $\%$ & $\mathrm{~N}$ & $\%$ \\
\hline \multicolumn{11}{|l|}{ Tipo de lesão } \\
\hline Amputação & 4 & 100 & - & - & - & - & - & - & 4 & 0.8 \\
\hline Disjunção & 1 & 100 & - & - & - & - & - & - & 1 & 0.2 \\
\hline Desbridamento & 1 & 100 & - & - & - & - & - & - & 1 & 0.2 \\
\hline Esmagamento & 1 & 100 & - & - & - & - & - & - & 1 & 0.2 \\
\hline Contusão & 5 & 25 & 9 & 45 & 3 & 15 & 3 & 15 & 20 & 4.3 \\
\hline Escoriações & 38 & 71.6 & 3 & 5.6 & 6 & 11.3 & 6 & 11.3 & 53 & 11.5 \\
\hline Fratura exposta & 51 & 80.9 & 5 & 7.9 & 2 & 3.1 & 5 & 7.9 & 63 & 13.7 \\
\hline Fratura fechada & 184 & 75.1 & 28 & 11.4 & 15 & 6.1 & 18 & 7.3 & 245 & 53.3 \\
\hline $\begin{array}{l}\text { Lesão de Partes } \\
\text { Moles }\end{array}$ & - & - & 3 & 50 & 3 & 50 & - & - & 6 & 1.3 \\
\hline Luxação & 21 & 72.4 & 2 & 6.8 & 3 & 10.3 & 3 & 10.3 & 29 & 6.3 \\
\hline TCE & 23 & 63.8 & 5 & 13.8 & 1 & 2.7 & 7 & 19.4 & 36 & 7.8 \\
\hline TOTAL & 329 & 71.6 & 55 & 11.9 & 33 & 7.1 & 42 & 9.1 & 459 & 100 \\
\hline \multicolumn{11}{|l|}{$\begin{array}{l}\text { Seguimento } \\
\text { anatômico }\end{array}$} \\
\hline Abdômen & 5 & 50 & 3 & 30 & 1 & 10 & 1 & 10 & 10 & 2.3 \\
\hline Cabeça e face & 40 & 70.1 & 7 & 13.2 & 2 & 3.7 & 8 & 15 & 57 & 13.4 \\
\hline Membros Superiores & 66 & 94.2 & - & - & 2 & 2.8 & 2 & 2.8 & 70 & 16.5 \\
\hline Membros Inferiores & 145 & 81.4 & 9 & 0.5 & 10 & 5.6 & 14 & 7.8 & 178 & 41.9 \\
\hline Região cervical & 1 & 33 & 1 & 33 & 1 & 33 & - & - & 3 & 0.7 \\
\hline Região Lombar & 1 & 33 & - & - & - & - & 2 & 66 & 3 & 0.7 \\
\hline Região Pélvica & 5 & 71 & 1 & 14.2 & - & - & 1 & 14.2 & 7 & 1.6 \\
\hline Tórax & 15 & 65.2 & 3 & 13 & 2 & 8.6 & 3 & 13 & 23 & 5.4 \\
\hline $\begin{array}{l}\text { Mais de um } \\
\text { seguimento }\end{array}$ & 69 & 94.5 & 8 & 10.9 & 4 & 5.4 & 3 & 4.1 & 73 & 17.2 \\
\hline TOTAL & 347 & 81.8 & 26 & 6.1 & 20 & 4.7 & 31 & 7.3 & 424 & 100 \\
\hline
\end{tabular}

A gravidade do trauma foi avaliada, por meio do NISS, as vítimas foram classificadas com trauma grave, moderado e leve. A partir do cálculo do NISS, foi verificada a presença de 10 pacientes com trauma grave, 36 com trauma moderado e 221 com trauma leve. Quanto à associação da gravidade do trauma com as características das lesões e da vítima, foi observado, conforme Tabela
4, que a ocorrência de lesão cerebral, lesão torácica e idade aumentam a chance de trauma grave, enquanto o estado civil casado diminui a chance, independente do sexo. Vale destacar que a lesão cerebral aumenta 5,37 vezes a chance de traumatismo grave e as lesões torácicas aumentam em 3,19 vezes.

Tabela 4 - Associação entre gravidade do trauma e características das lesões e vítima entre pacientes internados por acidente de trânsito, no município de Rio Branco, AC, no período de novembro de 2016 a abril de 2017

\begin{tabular}{llccc}
\hline Características & Categorias & OR ajustada & IC95\% & $P$ \\
\hline Lesão cerebral & Não & 1,00 & & \\
& Sim & 5,37 & $2,37-12,17$ & 0,000 \\
Lesão torácica & Não & 1,00 & & 0,025 \\
& Sim & 3,19 & $1,15-8,83$ & 0,049 \\
Estado Civil & Solteiro & 1,00 & & 0,033 \\
Idade (Anos) & Casado & 0,48 & $0,24-0,99$ & $1,00-1,06$ \\
Sexo & & 1,03 & & 0,03 \\
& Feminino & 1,00 & $0,38-2,08$ & 0,794 \\
\hline
\end{tabular}

Fonte: Pesquisa de Campo.

Os homens em idade jovem são as principais vítimas, quando tratamos de acidentes de trânsito, fato que aparece em acordo com outros estudos e pode estar associado à maior exposição pertencente ao comportamento sociocultural nessa categoria ${ }^{(7,12)}$.

Motociclistas são os mais envolvidos em acidentes, seguidos de pedestres, ocupantes de veículo fechado e ciclistas ${ }^{(3-4)}$. O crescimento de 
acidentes, envolvendo motociclistas, pode estar relacionado ao aumento da sua frota no país. Estado civil casado foi fator protetor, pois presume-se que muitos casados do estudo são indivíduos que possuam família e estão em um grupo etário mais experiente e com menos impetuosidade no tráfego ${ }^{(13)}$.

Relativo a período da semana, a maior frequência dos acidentes encontrou-se de segunda à sexta-feira, considerando a somatória de dias em maior número, quando comparado ao fim de semana, tendo assim aumento na chance dos acontecimentos. Além disso, a concentração de atividades de trabalho e movimentação viária durante a semana é maior ${ }^{(14)}$.

Outro ponto é a ocorrência de acidentes no período diurno, especialmente vespertino, que, em acordo com outros estudos, pode acontecer nesse intervalo pelo fato de o condutor dirigir cansado, com acúmulo de cobranças e pressões e ainda influência no clima ${ }^{(15-16)}$.

A natureza das lesões e a gravidade do trauma podem ser fatores influenciadores nos quesitos: tempo de internação, tipo de assistência prestada e condições para alta hospitalar. Desse modo, a assistência de enfermagem é fundamental, no tocante à identificação dos diagnósticos adequados, para cuidados sistematizados, com resultados positivos, a citar; dor aguda, integridade tissular prejudicada e risco para infecção, repercussões essas esperadas, visto que vítimas de acidentes de trânsito são frequentemente atingidas por múltiplos traumas, lesões extensas e complexas com perfuração de tecidos $^{(17)}$.

Igualmente a outras pesquisas ${ }^{(13,18)}$, no presente estudo, as fraturas apresentaram o maior número de casos, afetando principalmente motociclistas. Seguindo as fraturas, lesões múltiplas também foram comuns, além disso, também foi corriqueiro o acometimento de várias regiões do corpo. As vítimas de acidentes de trânsito são comumente caracterizadas como politraumatizados, situação que pode piorar seu prognóstico, necessitando de avaliação imediata ${ }^{(6)}$. Resultados como esse também podem ser encontrados em um estudo, em que $19,1 \%$ dos indivíduos foram acometidos por mais de um tipo de lesão(7).

Alguns estudos apontam a frequente ocorrência de escoriações, visto que esse tipo de agravo acometeu $28,7 \%$ dos $\operatorname{casos}^{(7)}$. Outra pesquisa ${ }^{(19)}$ também apresentou resultados semelhantes com $25,5 \%$ de escoriações e cortes, os quais diferem do encontrado, no presente estudo, em que apenas $11,5 \%$ dos casos apresentaram essa lesão. Isso pode ser justificado pela metodologia da pesquisa, cujos dados das lesões eram retirados dos prontuários dos pacientes que nem sempre estavam completos.

Outra injúria de comum ocorrência no trauma são os TCEs, que também são um importante agravante no prognóstico das vítimas $^{(6)}$. No presente estudo, os mais acometidos por esse tipo de ferimento foram motociclistas seguidos dos ciclistas; essas duas categorias de vítimas também foram as que tiveram a região da cabeça/face mais atingida. Pesquisas já apontam o elevado acometimento da região da cabeça tanto em motociclistas quanto em ciclistas ${ }^{(5,20)}$.

No que diz respeito às regiões anatômicas, a mais atingida foi a de membros inferiores, resultado confirmado por outras pesquisas, que apontam essa região como a mais frequentemente lesada em acidentes de trânsito ${ }^{(5,20)}$. Os motociclistas são o tipo de vítima mais acometida por injúrias, em extremidades e região pélvica, porque essas são as regiões mais desprotegidas, visto que o equipamento de segurança oferece proteção apenas para a cabeça ${ }^{(5,12-13)}$.

Quanto ao mecanismo do trauma, em ocupantes de veículo fechado, em caso de colisão frontal, a cabeça é o primeiro ponto de choque contra o para-brisa, o tronco é impelido contra o volante do carro e os membros também se chocam contra a parte inferior do painel ${ }^{(5)}$. Desse modo, é comum o achado de lesões na região de membros inferiores, cabeça/face, abdômen e tórax, como foi o caso do presente estudo, além de outros ${ }^{(6,21)}$.

Levando em consideração o AIS, houve maior ocorrência de lesões moderadas, seguidas de graves e por fim leves. Os motociclistas apresentaram principalmente agravos AIS $<3$, sendo a categoria que menos apresentou lesões graves, esse resultado corrobora com pesquisas que apontam um maior índice de ferimentos leves e moderados nessa categoria ${ }^{(22) .}$. Os motociclistas apresentaram principalmente agravos AIS $<3$, sendo a categoria que menos apresentou lesões graves.

As vítimas que apresentaram o maior número de casos AIS $>3$ foram os ocupantes de automóvel com $36,5 \%$. As injúrias que mais apresentaram AIS > 3 foram fraturas expostas, fraturas fechadas e TCEs, porém diversos estudos apontam a prevalência de lesões graves, em extremidades e região cefálica, principalmente, em motociclista $^{(20)}$. 
A gravidade do trauma pôde ser avaliada pelo NISS, pois houve mais casos de trauma leve, porém lesões cerebrais, torácicas e idade foram relacionadas à maior ocorrência de trauma grave. A idade é apontada como influenciador de prognóstico, nas diversas situações de traumas e, conforme apontado em estudos, os traumas cranioencefálicos são os mais frequentemente encontrados em casos graves e fatais ${ }^{(6,23)}$.

Destaca-se que o desfecho das lesões em óbito ou sequelas, apresentadas pela vítima de trauma, pode ser influenciado diretamente pela assistência prestada ao acidentado, e esse cuidado requer um conjunto de ações articuladas, integradas e contínuas, priorizando as medidas que visem prevenir e reparar agravos, proporcionando atendimento humano e holístico, desde imobilização do membro até a higienização corporal para o êxito no tratamento e bom prognóstico ${ }^{(24)}$.

Observando os dados encontrados, percebe-se a importância do profissional de enfermagem, na assistência ao politraumatizado, o que influencia na sobrevida da vítima. O conhecimento, a partir dos diagnósticos de enfermagem e as intervenções da NIC (Nursing Interventions Classification), favorece a promoção de uma assistência especializada, qualificada e integral com uma avaliação dos cuidados prestados, com base em um entendimento fisiopatológico e semiológico, agregados à experiência clínica. Assim, o processo de enfermagem é um instrumento primordial, pois proporciona um guia sistematizado para a realização do julgamento clínico(8-10).

\section{CONCLUSÃO}

De modo geral, o presente estudo reuniu dados, para traçar o perfil das vítimas e dos acidentes de trânsito, bem como as principais lesões que os acometiam e sua gravidade. Pôde-se perceber a prevalência de jovens do sexo masculino, separados por categoria, os motociclistas obtiveram o maior número de casos, sendo também os que mais apresentaram vítimas com trauma grave.

Com relação às lesões, houve maior frequência de fraturas, e o maior número de injurias graves estava nos ocupantes de veículo fechado. A região mais atingida foi a de membros inferiores, e os ciclistas apresentaram grande número de lesões na região da cabeça
Em se tratando dos pedestres, o reduzido número de indivíduos em tal categoria nos remete a pensar que, em virtude da gravidade das lesões, em grande maioria vão a óbito, no local do acidente ou no trajeto ao hospital, expondo assim a sua fragilidade e vulnerabilidade como usuário da via e rogando a necessidade imediata de medidas preventivas coerentes de respeito e responsabilidade pelo pedestre.

Além disso, os dados também podem servir de subsídios para novas pesquisas e orientação de conduta nos atendimentos de enfermagem, bem como na sistematização da assistência no trauma dentro do mnemônico XABCDE do trauma, visto que o conhecimento das lesões auxilia na percepção de risco, para intervenção imediata e para um bom prognóstico. Relativo às limitações encontradas no estudo, pôde-se perceber o precário fornecimento de informações, a respeito das lesões sofridas pela vítima, houve também dificuldade na captação de dados, em algumas fichas hospitalares, nas quais se observou ausência de informações sobre diagnósticos médicos e procedimentos realizados e, ainda, a ilegibilidade de determinados dados, sendo esses um dos grandes desafios ao se trabalhar com instrumentos de notificações diárias do atendimento hospitalar.

\section{REFERÊNCIAS}

1 - World Health Organization (WHO). Global status report on road safety 2015. Geneva: WHO; 2015 [cited 2017 Sept 19]. Available in: https://www.who.int/violence injury prevention/ road safety status/2015/en/

2 - World Health Organization (WHO). Injuries and violence: The facts 2014. Geneva: WHO; 2014 [cited 2017 Sept 19]. Available in: http://www. who.int/violence injury prevention/ media/news/2015/Injury violence facts 2014/en l

3 - Ministério da Saúde (BR). Óbitos por causa externas - Brasil 2018. Brasília: Ministério da Saúde; 2018a [citado em 18 abr 2020]. Acesso em: http://tabnet.datasus.gov.br/cgi/tabcgi.exe?sim/c nv/ext10uf.def

4 - Ministério da Saúde (BR). Morbidade Hospitalar do SUS por Causas Externas - Brasil 2018. Brasília: Ministério da Saúde; 2018b [citado em 18 abr 2020]. Acesso em: http://tabnet.datasus.gov.br/cgi/tabcgi.exe?sih/cn v/fiuf.def 
5 - Batista SEA, Baccani JG, Silva RAP, Gualda KPF, Vianna Júnior RJA. Análise comparativa entre os mecanismos de trauma, as lesões e o perfil de gravidade das vítimas, em Catanduva - SP. Rev Col Bras Cir. 2006;33(1):6-10. DOI: 10.1590/S010069912006000100003 ISSN 0100-6991

6 - Calil AM, Sallum EA, Domingues CA, Nogueira LS. Mapeamento das lesões em vítimas de acidentes de trânsito: revisão sistemática da literatura. Rev Latino-Am Enfermagem 2009;17(1):121-7. DOI: 10.1590/S010411692009000100019

7 - Gomes ATL, Silva MF, Dantas BAS, Dantas RAN, Mendonça AEO, Torres GV. Caracterização dos acidentes de trânsito assistidos por um serviço de atendimento móvel de urgência. J Res Fundam Care 2016;8(2):4269-79. DOI: 10.9789/21755361.2016.v8i2.4269-4279

8 - Cyrillo RMZ, Dalri MCB, Canini SRMS, Carvalho EC, Lourencini RR. Diagnósticos de enfermagem em vítimas de trauma atendidas em um serviço pré-hospitalar avançado móvel. Ver Latino-Am Enfermagem 2009;11(4):811-9. DOI: 10.5216/ree.v11i4.33235

9 - Caritá EC, Nini RA, Melo AS. Sistema de auxílio aos diagnósticos de enfermagem para vítimas de trauma no atendimento avançado pré-hospitalar móvel utilizando as taxonomias NANDA e NIC. J Health Inform. 2010 [citado em 15 mar 2020]; 2(4):87-94. Acesso em: http://www.jhisbis.saude.ws/ojs-jhi/index.php/jhi-

sbis/article/view/108/36

10 - Bertoncello KCG, Cavalcanti CDK, Ilha P. Diagnósticos reais e proposta de intervenções de enfermagem para os pacientes vítimas de múltiplos traumas. Rev Eletrônica Enferm. 2013;15(4):905-14. DOI: 10.5216/ree.v15i4.19497

11 - Rocha, GS. Fatores associados, gravidade do trauma e sequelas de acidentes de transporte terrestre [tese]. São Paulo: Universidade de São Paulo; 2015.

12 - Silveira JZM, Sousa JC. Sequelas de acidentes de trânsito e impacto na qualidade de vida. Saude e Pesqui. 2016;9(2):373-80. DOI: 10.17765/2176$\underline{9206.2016 v 9 n 2 p 373-380}$

13 - Soares LS, Sousa DACM, Machado ALG, Silva GRF. Caracterização das vítimas de trauma por acidente com motocicleta internadas em um hospital público. Rev Enferm UERJ 2015;23(1):115121. DOI: $10.12957 /$ reuerj.2015.15599

14 - Dias LKS, Vasconcelos AMB, Bezerra WMT, Albuquerque IMN, Lira GV, Pierre LPP. Caracterização dos acidentes de trânsito atendidos pelo serviço de atendimento móvel de urgência. Sanare 2017 [citado em 15 mar 2020]; 16(1):6-16. Acesso em:

file://C:/Users/Francinara/Downloads/11332760-1-SM\%20(1).pdf

15 - Albuquerque AM. Vítimas de acidente de moto com traumatismo. Rev Enferm UFPE 2016; 5(10):1730-8. DOI: 10.5205/reuol.9003-78704-1SM.1005201620

16 - Santos WJ, Coelho VMS, Santos GB, Ceballos AGC. Caracterização dos acidentes de trânsito envolvendo trabalhadores motociclistas em Pernambuco - 2016. J Health Biol Sci. 2018;6(4):431-6. DOI: 10.12662/23173076jhbs.v6i4.2113.p431-436.2018

17 - Cavalcanti CDk, Ilha P, Bertoncello KCG. O cuidado de enfermagem a vítima de trauma múltiplos: Uma revisão integrativa. UNOPAR Cient Ciênc Biol Saúde 2013;15(1):81-8. DOI: 10.17921/2447-8938.2013v15n1p\%25p

18- Sousa KM, Oliveira WIF, Alves EA, Gama ZAS. Fatores associados ao acesso à reabilitação física para vítimas de acidentes de trânsito. Rev Saude Publica 2017;51(54):1-13. DOI: 10.1590/S1518$\underline{8787.2017051006429}$

19 - Medeiros WMC, Galvão CH, Guedes ISC, Carício MR, Macedo EMF, Ribeiro LM. Perfil epidemiológico das vítimas de acidentes de trânsito atendidas num serviço público de emergência da região metropolitana de Natal/RN. Holos 2017;33(7):213-24. DOI:

10.15628/holos.2017.4876

20 - Paiva L, Monteiro DAT, Pompeo DA, Ciol MA, Dantas RAS, Rossi LA. Readmissões por acidentes de trânsito em um hospital geral. Rev Latino-Am Enfermagem 2015;23(4):693-9. DOI: 10.1590/0104-1169.0242.2623

21 Santos SMJ, Souza MA, Rocha FL, Souza VP, Muniz MAS, Rodrigues JÁ. Caracterização dos fatores de risco para acidentes de trânsito em vítimas atendidas pelo serviço móvel de urgência. Rev Enferm UFPE 2016;10(10):3819-24. DOI: 10.5205/1981-8963-v10i10a11448p3819-3824-

2016 
22 Petenuti A, Lopes L, Volpato RJ, Pessini MA. Caracterização das sequelas das vítimas de acidentes de trânsito com motocicleta em vias urbanas numa cidade da região noroeste do Paraná. Akrópolis 2016;24(2):131-42. DOI: 10.25110/akropolis.v24i2.6332

23 Santos AMR, Rodrigues RAP, Diniz MA. Trauma no idoso por acidente de trânsito: Revisão integrativa. Rev Esc Enferm USP 2015;49(1):16272. DOI: $10.1590 /$ S0080-623420150000100021

24 Santos, MAS da; Santos, LGES dos; Oliveira GFSM; Miranda LN. Assistência de enfermagem ao paciente politraumatizado. Ciências Biológicas e de Saúde 2018 [citado em 2 nov 2020]; 4(2):11-22. Acesso

em: https://periodicos.set.edu.br/fitsbiosaude/article/ view/4648/2777
Nota: Este artigo na íntegra faz parte do trabalho de conclusão de curso: "Caracterização das lesões traumáticas e sua gravidade em vítimas de acidente de trânsito internadas em um hospital público" do curso de bacharelado em enfermagem - Campus Rio Branco da Universidade Federal do Acre - UFAC

Recebido em: 24/06/2020

Aprovado em: 07/12/2020 